\title{
Buckup Klaus: Clinical tests for the musculoskeletal system, examinations, signs, phenomena (2nd edition)
}

\author{
Thieme Verlag, New York, Stuttgart, 2008, 326 pp, numer. figs, Softcover, \\ $€$ 39.95, CHF 67.90, ISBN: 978-3-13-136792-1
}

Pierre Kehr

Received: 15 August 2009 / Accepted: 18 August 2009 / Published online: 10 September 2009

(C) Springer-Verlag 2009

It is the second edition of a small opuscule taking again the clinical tests making it possible to direct the diagnosis and to avoid multiplying the complementary examinations.

The various tests are gathered by articulation: Hip, Knee Hand and Wrist.

There are also the disorders of the posture, venous thromboses and the arterial tests of occlusion.

For each test, the procedure, the result and the diagnosis evoked with possibly the differential diagnoses are described.
At the end of the book an index and a bibliography are quite useful.

One can regret the absence of indication on the relevance of the test, but this book remains nevertheless very interesting, as well for the students as for the seniors to refresh the memory or to find a forgotten test.

No funds were received in support of this study.

Alain Graftiaux
P. Kehr $(\square)$

Strasbourg, France

e-mail: kehrpier@aol.com 